\title{
Communication and Cognition in Primate Group Movement
}

\author{
Julia Fischer • Dietmar Zinner
}

Received: 28 December 2010 / Accepted: 26 May 2011 / Published online: 19 October 2011

C The Author(s) 2011. This article is published with open access at Springerlink.com

\begin{abstract}
We here review the communicative and cognitive processes underpinning collective group movement in animals. Generally, we identify 2 major axes to explain the dynamics of decision making in animal or human groups or aggregations: One describes whether the behavior is largely determined by simple rules such as keeping a specific distance from the neighbor, or whether global information is also factored in. The second axis describes whether or not the individual constituents of the group have overlapping or diverging interests. We then review the available evidence for baboons, which have been particularly well studied, but we also draw from further studies on other nonhuman primate species. Baboons and other nonhuman primates may produce specific signals in the group movement context, such as the notifying behavior of male hamadryas baboons at the departure from the sleeping site, or clear barks that are given by chacma baboons that have lost contact with the group or specific individuals. Such signals can be understood as expressions of specific motivational states of the individuals, but there is no evidence that the subjects intend to alter the knowledge state of the recipients. There is also no evidence for shared intentionality. The cognitive demands that are associated with decision making in the context of group coordination vary with the amount of information and possibly conflicting sources of information that need to be integrated. Thus, selective pressures should favor the use of signals that maintain group cohesion, while recipients should be selected to be
\end{abstract}

\footnotetext{
J. Fischer

Cognitive Ethology Laboratory, German Primate Center, University of Göttingen, 37077 Göttingen, Germany

J. Fischer

Courant Research Centre "Evolution of Social Behavior", University of Göttingen, 37077 Göttingen, Germany

D. Zinner $(\bowtie)$

Cognitive Ethology Laboratory, German Primate Center, 37077 Göttingen, Germany

e-mail: dzinner@gwdg.de
} 
able to make the decision that is in their own best interest in light of all the available information.

Keywords Baboons · Collective action · Communication - Intention · Papio

\section{Introduction}

Many species form aggregations or groups, including the majority of primates as well as humans. Whenever the advantages of group living for individuals outweigh the costs incurred by the disadvantages, such as increased transmission of pathogens or competition with group mates for food or mating partners, group living should be selected (Alexander 1974; Anderson 1986; Krause and Ruxton 2002; van Schaik 1983; Wrangham 1980). Once group living has evolved, animals are often faced with the need to choose, collectively, between mutually exclusive actions. The decision-making processes may pose additional costs on group-living animals. For example, decision making about the direction of the morning departure from a sleeping site in hamadryas (Papio hamadryas) or chacma baboons (P. ursinus) can take up to $1 \mathrm{~h}$ (Stolba 1979; Stueckle and Zinner 2008). In recent years, efforts have been made to understand how groups reach collective changes in their activity states, e.g., from resting to moving (Dostálková and Spinka 2007; Stueckle and Zinner 2008; Sueur et al. 2009; Sueur and Petit 2010; Sueur et al. 2011a, b), events that are crucial if individuals are to benefit from synchrony with other group members (Conradt 1998; King and Cowlishaw 2009; Ruckstuhl 1999).

We begin this review of the role of communication and cognition in coordinated behavior with a brief introduction of the current concepts that have been invoked to characterize coordinated behavior. We then turn to the study of baboons and review the evidence accumulated for group coordination. Specifically, we focus on the use of nonvocal and vocal signals to achieve coordinated behavior. To put the results for the baboons into a broader perspective, we also draw from studies in other nonhuman primate species. Next, we turn to the cognitive underpinnings of coordinated behavior in nonhuman primates in general, and discuss the differences between nonhuman primates and humans. We end with a brief outlook in which we identify promising future research areas.

\section{Current Concepts: From Rule-Governed Behavior to Complex Processing of Information}

The central issue in collective animal behavior is how individual decision making gives rise to collective behavior. Although the term group decision making is frequently used to describe the process that eventually leads to coordinated action, such group decisions are based on the behavior of individuals (Seed et al. 2011). For example, in contrast to individual decision making in relation to food distribution or perceived risk, group decision making is of interest because individual decisions strongly depend on the behavior of others and are thus not independent of each other, resulting in specific dynamics of certain behaviors at the group level (Sumpter 2006). 
The fact that individual subjects make specific decisions raises the question of whether they have only local (subjects simply pay attention to what their neighbors are doing) or also global information and whether the individual interests overlap or diverge and of how subjects integrate environmental and behavioral information to make their choices. The first 2 questions can be depicted along 2 major axes (Fig. 1) explaining the dynamics of decision making in animal or human groups or aggregations: 1) the behavior is organized at the local or global level; 2) interests of individual group members overlap or diverge; 3 ) these processes are embedded in the physiological and ecological conditions, which may pose specific constraints (Conradt et al. 2009).

In terms of the processes giving rise to collective action, there are unfortunately a number of different, partly overlapping, and not fully compatible concepts (Pyritz et al. 2011). To make matters worse, the terms are not always used consistently, and a number of terms are adopted that describe highly complex human social institutions (see Conradt et al. 2009 for an overview of terms used in the natural and social sciences). In some cases, such a transfer of terms appears to have larger metaphorical than explanatory power.

\section{Local and Global Information}

Many people may know the example of collective behavior of starlings (Sturnus vulgaris) when they perform their spectacular acrobatic swarm movements on their way to their autumn sleeping sites. Such seemingly complex group behaviors can be generated by rules that govern the behavior locally, without any information at the individual level about the global movement pattern. These processes have been described as self-organization (Camazine et al. 2001). In principle, the behavior of swarms can be generated by modeling individuals as self-propelled particles linked to their neighbors through attraction, repulsion, and alignment. Directed behavior of large groups, as well as more complex behaviors such as the confusion of predators, can be explained by these simple rules (Gregoire et al. 2003). The issue becomes more complex when individuals possess both local knowledge about the behaviors of those around them and global knowledge about some aspect of the environment. When the 2 types of information are not in agreement, subjects need to make decisions. Take, for instance, a situation at the airport wherein a crowd is exiting the

Fig. 1 Conceptions of the processes underlying group decision making. Two of the major determinants are the distribution of information (local vs. global overview) and the distribution of interests (overlapping vs divergent). Within this framework, more detailed characterizations are possible. Note also that local and global processes may interact.

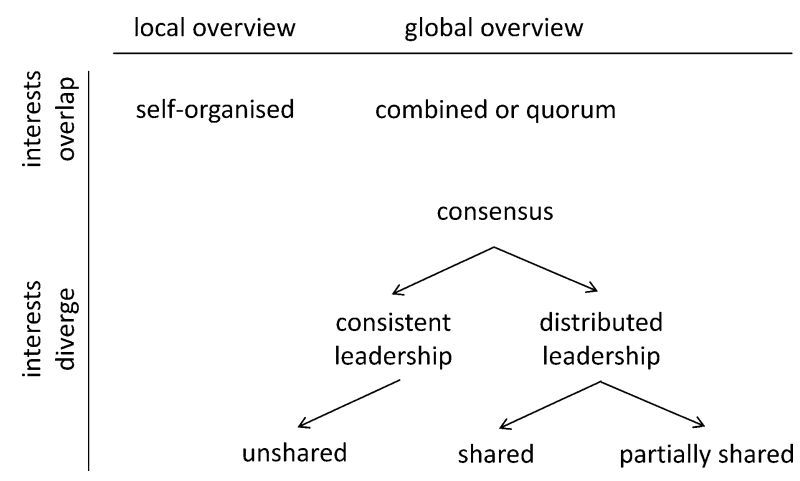


arrival hall through 1 of 2 doors, although the other door is also clearly marked with the word Exit. You may be inclined to factor in that global information and leave through the second door, or you may be influenced by other people's behavior and walk with the crowd, possibly assuming that some of them must know that the other door is locked. In such cases, conflicts of interest may occur and individuals have to consider the costs (checking if the door is locked requires the risk of wasted time and energy) and benefits (less inhibited exiting) of choosing one alternative over another.

A subject's probability of exhibiting a given behavior is a sharply nonlinear function of the number of other individuals already performing this behavior. This phenomenon has been described as quorum response (Sumpter 2006). Quorum sensing has also been invoked to explain the collective action of bacteria. For instance, individual bacteria are able to detect the number and strain identity of other bacteria around them, and vary their behavior, e.g., biofilm production, accordingly (Nadell et al. 2008). In bacteria, quorum sensing is based on the secretion and detection of autoinducer molecules. The concentration of these molecules gives some indication of the cell density in that particular area. Once concentrations of these molecules have reached a certain threshold, it affects the behavior of quorumsensing cells. Quorum sensing has been linked to a number of other processes in bacteria, including sporulation and bioluminescence (Miller and Bassler 2001), and constitutes one of the simplest means of achieving collective action in social organisms.

A more complex example in which quorum sensing and decision-making both play a role is the emigration of an insect society from an old nest to a new one. This requires the assessment of different sites, a comparison between them, and an eventual choice of the new nest site (Pratt et al. 2002). Once a suitable new nest site has been found, the entire colony needs to be moved there. Several studies have shown that honey bee (Apis mellifera) and ant colonies are able to achieve this goal without any central control. These cases constitute intriguing examples for studying the link between behavioral rules and the flow of information between individual members. The ant Leptothorax albipennis, for instance, achieves the selection of a new site on the basis of a process in which several individuals function as scouts. Once a scout has identified a suitable site, it returns home. The initiation of recruitment behavior is inversely proportional to the quality of the site, thus providing some indirect information about site quality (Pratt et al. 2002). The recruitment occurs in the form of so-called tandem runs. Once a certain number of individuals are found at the new site (quorum sensing), tandem runs are abandoned in favor of transport runs in which passive members are carried to the new site. In sum, a combination of relatively simple rules is sufficient to achieve such a complex collective action as the move of a colony to a new nest site. Quorum sensing is also found in smaller groups with individuals having higher cognitive abilities such as meerkats (Suricata suricatta: Bousquet et al. 2011) and Tonkean macaques (Macaca tonkeana: Sueur et al. 2009, 2011a, b; Sueur and Deneubourg 2011). For example, moving calls emitted by meerkats increased the speed of the group, with a sharp increase in the probability of changing foraging patch when the number of group members joining the chorus increased from 2 up to 3 (Bousquet et al. 2011). 


\section{Overlapping and Diverging Interests}

When interests overlap, collective behavior may arise through combined decision making (Conradt and Roper 2005). In a combined decision, there is no conflict of interest and external stimuli direct individual decisions in the same direction. However, the term combined decision has been regarded as ambiguous because it cannot be separated clearly from the term quorum decision in which group members also choose individually between different options until a certain threshold is reached that affects the entire group (Pyritz et al. 2011). An example of a combined decision is provided by a herd of thirsty animals walking to the nearest water source. When interests diverge, subjects need to reach consensus decisions. Such scenarios raise the question of whether specific individuals exert a disproportionate influence on the outcome of behavior, e.g., because of their social role in the group or because of an uneven distribution of information. In such cases, animals can be characterized as leaders and followers (King and Cowlishaw 2009). Researchers have proposed 2 principal forms of leadership: 1) personal leadership (unshared) wherein a single individual uses its high dominance status or experience to lead the group, resulting in an unshared decision; 2) distributed leadership (shared consensus), wherein either all group members reach an equally shared decision, or a subgroup of individuals reaches a partially shared decision (Conradt and Roper 2005; Leca et al. 2003). In cases of divergent interests, decision making also requires some form of interaction among the involved individuals, whereas a combined or quorum decision can be achieved without any such interaction. Hence, consensus decisions are also described as aggregate or collective decisions, whereas combined or quorum decisions are described as interactive decisions (Conradt et al. 2009).

The case of mountain gorillas (Gorilla beringei) is often cited as an example of unshared decision making (King and Cowlishaw 2009; Petit and Bon 2010), wherein the silverback male directs the group by heading in his preferred direction (Watts 2000). In this example, the apparently coordinated behavior is based on the fact that other group members have no choice but to follow the leader if group cohesion is to be maintained. Similar processes have also been observed in mongooses (Helogale parvula undulates [Helogale undulata rufula]: Rasa 1983) and wolves (Canis lupus: Mech 1970). However, in these examples, predeparture processes (grunts or group ceremony) exist that may indicate at least some form of behavioral adjustment to synchronize the departure time. In wolves, it seems that leadership is at least shared between the partners of the dominant pair (Peterson et al. 2002). It remains therefore unclear whether unshared decision making in its pure form actually exists (Bourjade and Sueur 2010). Shared decisions are generally thought to be more profitable for group members than accepting unshared decisions made by a single leader (Conradt and Roper 2007), because on average there is a greater overlap of interest.

Researchers have observed distributed leadership in such diverse species as honeybees (Seeley and Buhrman 2001), coatis (Gompper 1996), and red deer (Conradt and Roper 2003). Note that in relation to group movements, leadership often refers to individuals initiating movements or changes in direction that are followed by the rest of the group (Leca et al. 2003; Trillmich et al. 2004). These animals are not necessarily the decisive subjects when it comes to agreeing on a certain direction. In a recent study, Conradt and colleagues showed that the 
assertiveness with which animals opt for one option over another depends on the cost of splitting, compared to the benefits of going to the leader's preferred target. The assertiveness, in turn, can be thought of as a function of meeting an individual's need. Animals that are highly motivated to direct the travel to a water source because they are thirsty may have a disproportionate effect on the group's eventual travel direction than less needy individuals (Conradt and Roper 2009). Exactly such a relationship between nutritional needs and leadership was also found in an agent-based model by Sueur et al. (2010). Conradt and Roper explored the conditions under which unshared decisions are - in evolutionary terms - more successful than shared ones. Using a combination of self-organizing systems and game theory, they revealed that shared as well as unshared decision types can evolve without invoking global knowledge in the individual members of a group. They found that unshared decisions are favored when conflicts are high compared to grouping benefits owing to the inherent expediency and simplicity of unshared decisions (Conradt and Roper 2009).

\section{Information Processing}

Animals' decisions on where to move can be influenced by information garnered from a variety of sources. One of these sources is the signaling behavior of other animals. Signals are defined as structures or behaviors that have been selected because they affect the behavior of others (Scott-Phillips 2008). In contrast to signals, cues are considered to reflect more directly the physiological or morphological state of an individual. Thus, cues encompass all sorts of features or behaviors that may influence a specific animal's actions (Maynard Smith and Harper 2003). Note that not all authors use these terms consistently, but it is generally agreed that signals evolve from cues, which in turn are a subset of an animal's behavioral features.

Importantly, from the recipient's point of view, signals are not necessarily more informative than cues or the simple behavior of another subject (Fischer 2011). In other words, if one animal watches another animal move in a certain direction, there is no doubt that the animal is doing just that: moving into a certain direction. In contrast, signals typically predict imminent behavior, but not necessarily fully reliably (Maynard Smith and Harper 2003). Nevertheless, signaling is important because it constitutes a source of (potential) information for the recipient and a relatively cheap way for the sender to aim to influence the behavior of others (Fischer 2011). The signaling involved in collective action may take a variety of forms, including the secretion of chemicals in bacteria that lead to quorum sensing, as well as the waggle dance of bees or the usage of vocal signals by baboons (Wheeler et al. 2011). In this sense, one may also distinguish between passive and active recruitment (Ramseyer et al. 2009). In the first case, animals would simply follow a moving animal; in the second case, the leader would reveal specific behaviors, including possibly signals, to increase the likelihood that others will follow.

\section{Baboons as Models to Study Animal Group Coordination}

Social organization and social structure vary among species and populations (Kappeler and van Schaik 2002) and group decision-making processes are expected 
to vary accordingly. For instance, group coordination and decision making in a pairliving species in which pair partners have tight social relationships are most likely not the same as in a species in which a large group of $>100$ individuals needs to be coordinated. Likewise decision making in strongly hierarchically structured groups most likely differs from decision making in more egalitarian systems. Also, group coordination in fission-fusion societies, in which either individuals or subgroups have to decide not only, e.g., where and when to move but also with whom, are of particular interest (Sueur et al. 2011a, b). A comparative study of group coordination in closely related species with varying social organizations and social structures is a promising approach to elucidate the relationships among the social system, information transfer, and group coordination. One such model is baboons, and so it is perhaps not surprising that the initiation of group movements and the coordination of travel have been studied extensively in this taxon (Byrne et al. 1989; King et al. 2008; Kummer 1995; Norton 1986; Sellers et al. 2007; Stolba 1979; Stueckle and Zinner 2008).

Baboons range all over sub-Saharan Africa and the Arabian Peninsula. They inhabit a large range of different habitats and exhibit very different social systems (Swedell 2011). Hamadryas baboons, for instance, live in a multilayered society that consists of small 1-male units (OMUs) of 1 male with a few females (Grueter and Zinner 2004; Kummer 1968). Several OMUs may form a clan, which forage together and that are thought to be connected by close kin relationships among the male leaders of the OMUs (Abegglen 1984; Schreier and Swedell 2009). Several such clans form a band, which shares a common home range and can include $>100$ individuals. Bands are seen as the ecological units of the hamadryas society, whereas OMUs are seen as reproductive units (Barton 2000; Dunbar 1988; Kummer 1990). Individuals rarely change from one band to another. Several bands may aggregate at certain rare sleeping cliffs where they spend the night and form troops of up to several hundred individuals (Kummer 1968; Zinner et al. 2001).

\section{Baboon Group Coordination}

In hamadryas baboons members of a band leave their sleeping cliff together at the same time and in the same direction. Each morning before leaving the sleeping site, a significant amount of time is devoted to agreeing on a joint direction of travel. Hans Kummer, who pioneered the study of group movement initiation, distinguished between initiative individuals (I) and decision-making individuals (D) and termed the system the ID system. The initiative and decision-making individuals are males, mainly older ones, with leaders of OMUs having apparently the greatest influence in the decision-making process (Kummer 1968). Kummer concluded that leading individuals do not need to determine group movement from the vanguard position because it is also possible to lead the troop from the back (Kummer 1968; Stolba 1979). Thus, hamadryas baboons provide an example of partially shared leadership (Kummer 1968; Leca et al. 2003).

Geladas (Theropithecus gelada), close relatives of baboons, live in a social organization superficially similar to that of hamadryas baboons. However, here the dominant female of the OMU fulfills a pivotal role in maintaining coordination between the male and his other females. Progressions are usually initiated by 
lactating females, but decisions whether to follow or not are shared by the dominant female and the male. Females monitor the behavior of the male but try to stay in proximity to their preferred social partners at the same time (Dunbar 1983).

In contrast to hamadryas baboons and geladas, savannah baboons typically live in female-bonded multimale, multifemale societies (Swedell 2011). Savannah baboons encompass the traditionally recognized morphotypes of chacma (Papio ursinus), yellow (P. cynocephalus), and olive baboons (P. anubis) (Jolly 1993). Because of the importance of females as the social core in these groups (Melnick and Pearl 1987; Swedell 2011), it became of interest to elucidate their role in initiating group movements. In a study in South Africa, Stueckle and Zinner (2008) examined whether distributed leadership included females. Before setting off for their daily march, these baboons rested below their sleeping trees. After some time, 1 individual (the initiator) moved away from the rest of the group. In such instances, others either followed (successful attempt) or stayed behind (unsuccessful attempt). The minimum number of consenting adult individuals that normally guaranteed that the entire group would depart was 5. Therefore, 6 adult individuals (initiator and 5 followers) seem to be sufficient to pull the entire group of 39 into the pursued direction, making the initiative successful. If not enough individuals followed, the initiator normally moved back to the group until a second attempt was made, either by the first initiator or another individual. Approximately $75 \%$ of all adults successfully initiated a collective move, with $67 \%$ of initiations being made by males. The relative success of an initiation was equally distributed among adult group members, with almost two thirds of the initiatives being successful. If a successful initiation of a collective move is regarded as equivalent to leadership, then these baboons show a system of distributed leadership. However, although the probability of being successful was similar for males and females when initiating a move, males had more influence on the morning departure process by initiating more start attempts, thereby making appreciably more successful initiations. Among males, there was a trend for higher-ranking (more dominant) individuals to make a higher total number of initiation attempts as well as a higher number of successful attempts than lower-ranking ones. No similar trend was obvious in females, most likely because a possible effect of dominance was masked by a confounding effect of females' reproductive state. High-ranking females were the ones with dependent offspring, which most likely forced them to stay in the center of the group or in close vicinity of a male protector instead of taking the lead when leaving the sleeping site (Stueckle and Zinner 2008).

In contrast, King and colleagues (2008) reported that the decision-making process was unshared and not distributed in another chacma baboon population. In this study, an artificial clumped food source was offered in the home range of a baboon group. The baboons had to decide whether to visit the feeding site or to go elsewhere to forage. When visiting, the dominant male obtained the largest share of the resource, while others received less or nothing at all. Nevertheless, the group's foraging decisions were consistently made by the dominant male. Subordinate group members followed the leader in the interest of staying together despite considerable consensus costs (no food) to these subordinate members. King and colleagues attributed the behavior of the subordinates to the value of their social bonds with the dominant male. These baboons seem to face a dilemma: either to maintain close 
proximity to the dominant male by following him to his preferred feeding site even though they do not benefit from the food, or leave the dominant male and forage on their own, thus jeopardizing their social relationship with the dominant male (King et al. 2008). However, the observed pattern was confined to the experimental situation in which baboons were provided with a clumped food source. Under more natural foraging conditions, the leadership was more evenly distributed across the group (King et al. 2008), as in Stueckle and Zinner (2008).

Guinea baboons (Papio papio) are the least studied baboons, but there are some indications that their social system differs from the hamadryas and savannah baboon systems. Guinea baboons live in large troops of several hundred individuals (GalatLuong et al. 2006; Sharman 1981) but neither larger stable bands of up to 120 individuals (as in hamadryas baboons) nor medium-sized groups of to 60 individuals (as in savannah baboons) are observed regularly. Moreover, stable 1-male units seem not to be the modal basic entity of Guinea baboons' social organization (Patzelt et al. 2011). Parties of several adult males and females (20-30 individuals) are found, but individuals are able to change from one such party to another without problems (Patzelt et al. 2011). Variation in party sizes, on both daily and seasonal scale, is high with a high degree of fission and fusion. Whether such a fluid system demands a more complex decision-making and a greater effort for group coordination than in more stable groups needs to be explored (Lusseau and Conradt 2009; Ramos-Fernández et al. 2011).

\section{The Use of Nonvocal Signals in Baboon Group Coordination}

During the decision-making process, particular behaviors or postures may be used to communicate (Heinroth 1911; King and Sueur 2011; Sueur and Petit 2010). In hamadryas baboons, males seem to communicate intensively during the decisionmaking process and negotiate the direction of travel (Kummer 1995; Stolba 1979). Males present to each other in a particular way, called notifying. Notifying can be a complete behavioral sequence entailing the approach of 1 male to within arms reach of another, turning the body, presenting the hindquarter, and looking back to the first male, who can then touch the penis of the presenting male. The mildest form of this behavior is just a short glance of 1 male to a second, followed by an abrupt turn of the glancer's head. Notifying is normally accompanied by vocalizations by both males. When proposing a certain direction, males may walk in a particular manner in the preferred direction or they may stand on outstretched arms and legs, as stiff as a sawhorse, and then advance in the direction of the body axis. A male can also vote against a proposed direction by sitting down and abruptly lowering his head onto his chest without moving for $2 \mathrm{~min}$. Possible equivalent behavioral patterns in chacma baboons include the presence or absence of a back glance when the initiator looks back to the rest of the troop while walking away, pauses of the initiator during locomotion, and walking speed of the initiator, either trotting or walking fast away from the troop. Such behaviors have been interpreted as intentional signals to recruit group members in capuchins (Cebus capucinus: Meunier et al. 2008). This view is also in line with the classic ethological concept that these signals have evolved from intention movements, which are viewed as expressions of the motivation to move. 
The Use of Vocal Signals in Baboon Group Coordination

Vocal signals play an important role in baboon group movements. It has been assumed that calls indicate the motivational state of the sender and provide some information about the sender's propensity to take a certain action (Fischer 2008). Moreover, such signals can facilitate emotional contagion, thus raising the probability of collective action such as a group departure (Fischer 2008). Chacma baboons emit soft tonal calls, called grunts, to facilitate social interactions with others or when they are travelling (Meise et al. 2011). Moreover, baboons utter grunts not only when they are moving through high grass, but also when the group is about to initiate a group movement in the morning or after the group has taken a rest during the day. A pilot study on a Namibian population of baboons indicated that an increase in the call rate reflects an increased probability that the group will start moving (Fig. 2). Although this system deserves further detailed study, it suggests that each individual's calling can be viewed as the expression of its motivation to get going. Once a certain number of individuals are grunting at the same time, this predicts that others are willing to follow if the first individual sets itself in motion. This system would also lend itself to experimental testing, as the grunt rate could be experimentally augmented. Similarly to baboons, vervets (Chlorocebus pygerythrus) utter "move into open" grunts when they sit near trees and before entering the open grassland (Cheney and Seyfarth 1982), whereas Barbary macaques (Macaca sylvanus) emit soft tonal calls termed girneys when they initiate group movements (Fischer and Hammerschmidt 2002). Finally, mountain gorillas also increase their individual call rate and more group members call before changing a feeding or resting site (Stewart and Harcourt 1994; Watts 2000).

In the context of group travel, chacma baboons also frequently emit barks, which have a tonal structure (Fischer et al. 2001, 2002) and are emitted when subjects have lost contact with specific individuals - for instance, their offspring — or with the rest of the group. Typically, several individuals can be heard calling at the same time, giving rise to the notion that they "answer" each other's calls. Cheney and

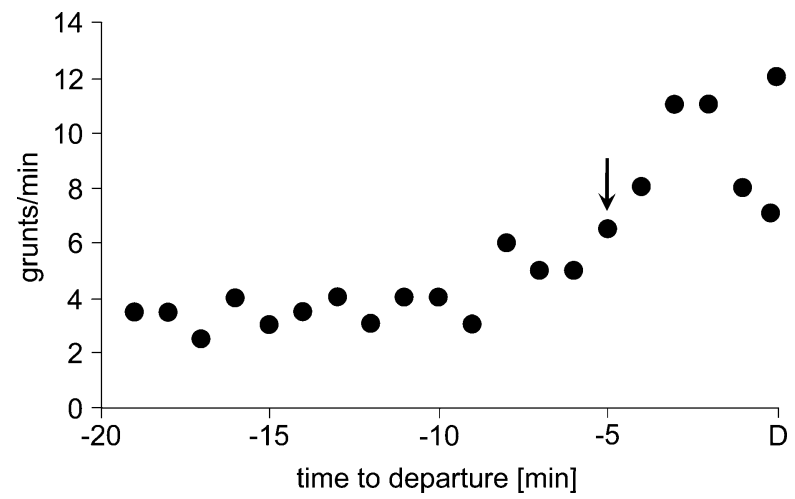

Fig. 2 Baboon grunts as cues to imminent group departure. Average grunt rate per individual and minute recorded at the sleeping site of baboons at Tsaobis (Namibia) before departure (D). The arrow indicates a significant increase in call rate (determined by means of a change-point analysis) about 5 min before the first individual's leaving. (Data were kindly made available by Kristine Meise, Christina Keller, and Guy Cowlishaw). 
colleagues set out to test this assumption in a group of baboons in the Okavango delta in Botswana (Cheney and Seyfarth 1996). They followed the adult females of the group for $2.5 \mathrm{~h}$ after the departure from the sleeping site and noted for each call the identity of the caller, the context, and the relative location of the individual compared to the rest of the group (front, middle, or rear). The observers were able to ascertain the identity of the caller and her location for $>1600$ calls. More than $80 \%$ of calls were given by individuals in the rear third of the group. A sequential analysis revealed that these calls typically occurred in a clumped fashion, with one signaller emitting several calls in succession, and several individuals calling at the same time. In fact, $92 \%$ of calls occurred within 5 min of another call, either following another subject's call, or because the individual was emitting a series of calls in a bout. A more detailed inspection revealed that calling was primarily driven by the caller's risk of becoming lost (hence, these calls have also been termed lost calls). To examine this finding systematically, Cheney and colleagues played back the clear barks of females to close female relatives, and then tested whether they would answer their kin. In 7 of 36 trials, the subject indeed responded to the playback with a vocal response within $5 \mathrm{~min}$. However, as in the previous observational study, these females were themselves lagging behind the group, suggesting that the immediate context and the risk of getting lost drives the calling behavior, and not the intention to inform the other group member about one's own location (Cheney and Seyfarth 1996).

Contact-calling may be influenced by the visibility (or lack thereof) of the location of other group members. Accordingly, one would predict that animals call more frequently when visibility is poor. Indeed, in Botswana, clear calls occurred more frequently in woodland habitat than on open flood plains, or when the group gathered near their sleeping trees (Cheney and Seyfarth 1996). Similarly, the rate of grunts given by olive baboons in Uganda varied with habitat type: baboons uttered grunts at a significantly higher rate in forest than in open habitat (Ey et al. 2009). In a population of olive baboons in Nigeria, in contrast, the grunt rate did not vary with the habitat quality and the visibility conditions. However, in both cases, the calls were significantly longer in the forest compared to the open habitat (Ey and Fischer 2011; Ey et al. 2009). Moreover, the rate of loud calls in Nigeria did not differ in relation to habitat. This suggests that calling rates are not simply determined by visibility. This observation raises the question of whether the differential call rate of chacma baboons in Botswana could be indirectly mediated by the fact that, in this group, individuals lose contact with the others less frequently in open habitats, while the much smaller group in Nigeria is generally more cohesive.

\section{Cognition and Collective Behavior}

Humans like to think of themselves as highly cognitive creatures who deliberately consider different outcomes of specific actions before taking a decision. Frequently, humans believe that they are approaching an optimum when doing so. Yet, they often rely on simple heuristics (Gigerenzer 2001). Morgan pointed out that "In no case is an animal activity to be interpreted in terms of higher psychological processes, if it can be fairly interpreted in terms of processes which stand lower in 
the scale of psychological evolution and development" (Morgan 1903, p. 59). This should also apply to the human animal. Therefore, considering coordinated behavior in putatively more simple organisms is useful in identifying how minimal sets of rules can give rise to collective action without the need to invoke cognitively demanding operations. For instance, a number of studies have shown how simple local processes govern the movement patterns of human crowds (Dyer et al. 2008).

At the same time, it is also of interest to clarify how cognitively elaborate group decision-making processes in animals can be. One important issue here is the question of whether the use of signals (or other forms of behavior) can be considered as intentional. In the domain of animal communication and cognition, researchers frequently invoke the definition of Dennett (1971). Dennett described different stages of intentionality, wherein 0 -order intentionality would apply to simple expressions of emotion or fixed action patterns given in response to sign stimuli. First-order intentionality describes communicative acts employed to alter the behavior of the recipient. This does not necessarily imply that the signaler is conscious of her own behavior or mental state (Bruner 1981) in the sense that the sender is aware that she does have such an intention. Tomasello and Call (1997) proposed that the observation that animals use different means to achieve a specific goal constitutes a diagnostic for (first-order) intentionality. Second-order intentionality would apply to cases in which the sender intends to alter the knowledge state of the other but not necessarily his or her immediate behavior. For second-order intentionality to apply, the sender must know that the receiver's mental state can be different from its own mental state. So far, there is no convincing evidence for second- (or higher-) order intentional communication in animals (Seyfarth and Cheney 2003). Thus, most studies ask whether primates use signals with the intention to alter their group mates' behavior.

For our specific purposes, Dennett's scheme is powerful because it clearly distinguishes between the intent to alter the mental state vs. the behavior of another subject. This research falls under the umbrella of "Theory of Mind" research, a field that investigates the attribution of beliefs, desires, and knowledge to others. The term was introduced by Premack and Woodruff (1978) in a paper entitled "Does the Chimpanzee Have a Theory of Mind?" To date, there is some evidence that nonhuman primates indeed understand something about the link between seeing and knowing (Hare et al. 2000; Kaminski et al. 2008), but they appear to lack a fullblown attribution of mental states. Thus, it seems fairly safe to conclude that nonhuman primates use signals with the possible intention to alter the movement patterns of others (Hesler and Fischer 2007), but they do not call with the intention of providing others with the information that they are about to leave (Fischer 2008; Seyfarth and Cheney 2003). Accordingly, Couzin (2009) suggested that the field of animal collective action may profit from studying the properties of neural assemblies and the information flow in such systems instead of invoking higher-level cognitive processes. Generally, one may conclude that selective pressures should favor the use of signals that maintain group cohesion; the usage and structure of such signals may be largely innate and do not require much cognition (Wheeler et al. 2011). In contrast, recipients should be selected to be able to make the decision that is in their own best interest in light of all the available information. Thus, selection should favor increased cognitive capacities and the ability to weigh different sources of information before coming to a decision. 
Differences in mental state attribution have important implications for the conceptualization of collective action and mechanisms underlying decision making. According to Bratman (1992), shared collective action refers to situations in which (human) subjects have a concept that a given activity is shared, and that each subject intends that the group performs the collective action by coordinating "subplans that mesh" (Bratman 1992). For instance, each member in a team of soccer players will assume that all the other team members have the same intention, i.e., to win the match, and also assume that the others are aware of the communality of that aim. Along these lines, Tomasello pointed out that human communication is grounded in fundamentally cooperative and shared intentions (Tomasello 2008). In contrast, no such cognitive assumptions are made in the animal domain.

The general problem with the study of intention in nonverbal creatures is that we are confined to infer the intention from the observable behavior, which typically leads to post hoc explanations. More powerful diagnostics are cases wherein an animal apparently does not achieve a specific goal. Here, we may be able to predict that the behavior should be repeated or exaggerated, either until the presumed goal is achieved, or until the subject shows signs of frustration.

For the time being, we consider searches for higher-order intentionality in nonhuman primates under field conditions futile. The challenge lies in devising field experiments that tap into first-order intentionality. For instance, field playback experiments have shown that listeners attribute directedness to specific calls. Specifically, after agonistic interactions, they assume that friendly grunts are directed at them, which is also a form of intentionality. Hearing such friendly grunts prompts the listener to interact with the previous aggressor more quickly than in the absence of such conciliatory grunts, e.g., chacma baboons (Engh et al. 2006). In the context of group movement and group coordination, the challenge is to create situations that put senders into different intentional states, or to devise experiments that reflect possible differences in terms of the sender's intentions, and then to study how other group members process and respond to the corresponding variation in behavior.

\section{Summary and Outlook}

Overall, we are now able to describe the patterns underlying group movements in nonhuman primates with regard to a number of dimensions, such as the level at which information is processed and the way decisions come about. Baboons constitute a valuable model, as appreciable evidence has been collected in a number of studies. The challenge is now to piece this information together and assess the putative influence of variation in social systems and group composition on decision making and group coordination in this taxon. In terms of the cognitive and communicative behaviors accompanying group movement, there are numerous examples in which signals play a role in achieving coordinated group movement. One important research question is whether signals constitute a relatively cheap means of generating similar motivational states in animals, which then foster coordinated action. There is increasing evidence for a close link between perception and action. Thus, hearing a specific call would increase the likelihood of the activation of the similar call type in the recipient, which in turn might activate the 
respective motivational state (Fischer 2008). In baboons, "waves of nervous grunting sweep the troop" (Dorothy Cheney pers. comm.). Such contagious behaviors may be sufficient to generate coordinated behaviors without the need of invoking higher cognitive processes and mental state attributions. The challenge for the future is to study such processes in more detail and to understand the evolutionary implications of such group-level behaviors. Granted, nonhuman primates may not be the ideal study subject because it is often difficult to monitor the behavior of several individuals at the same time. Specific settings such as departures from sleeping sites or before individuals embark on water crossings may lend themselves to further study. Telemetric devices (in combination with GPS) could also be used to keep track of the activity levels of several subjects at the same time. For the time being, the study of the fitness consequences will probably be confined to model systems with a shorter lifespan and to modeling approaches.

Acknowledgments We thank the guest editors, Andrew King and Cedric Sueur, for the invitation to contribute to the special issue of the International Journal of Primatology. We thank Kristine Meise, Christina Keller, and Guy Cowlishaw for making unpublished data available and we thank the reviewers for their helpful comments. This article is partly based on a book chapter published in Boos M, Kolbe M, Ellwart T, Kappeler PM, Eds. (2011) Coordination in human and non-human primate groups. Heidelberg: Springer. The revised version benefited greatly from Joanna Setchell's careful editing suggestions. This work was funded by the German Initiative of Excellence.

Open Access This article is distributed under the terms of the Creative Commons Attribution Noncommercial License which permits any noncommercial use, distribution, and reproduction in any medium, provided the original author(s) and source are credited.

\section{References}

Abegglen, J. J. (1984). On socialization in hamadryas baboons. Lewisburg: Bucknell University Press. Alexander, R. (1974). The evolution of social behavior. Annual Review of Ecology and Systematics, 5, 325-383. Anderson, C. (1986). Predation and primate evolution. Primates, 27, 15-39.

Barton, R. A. (2000). Socioecology of baboons: The interaction of male and female strategies. In P. M. Kappeler (Ed.), Primate males: Causes and consequences of variation in group composition (pp. 97107). Cambridge: Cambridge University Press.

Bourjade, M., \& Sueur, C. (2010). Shared or unshared consensus for collective movement? Towards methodological concerns. Behavioural Processes, 84, 648-652.

Bousquet, C. A. H., Sumpter D. J. T., \& Manser, M. B. (2011). Moving calls: A vocal mechanism underlying quorum decisions in cohesive groups. Proceedings of the Royal Society B: Biological Sciences. doi:10.1098/rspb.2010.1739.

Bratman, M. E. (1992). Shared cooperative activity. Philosophical Review, 101, 327-341.

Bruner, J. S. (1981). Intention in the structure of action and interaction. Advances in Infancy Research, 1, 41-56.

Byrne, R. W., Whiten, A., \& Henzi, S. P. (1989). Social relationships of mountain baboons: leadership and affiliation in a non-female-bonded monkey. American Journal of Primatology, 18, 191-207.

Camazine, S., Deneubourg, J., Franks, N., Sneyd, J., Theraulaz, G., \& Bonabeau, E. (2001). Selforganization in biological systems. Princeton: Princeton University Press.

Cheney, D. L., \& Seyfarth, R. M. (1982). Recognition of individuals within and between groups of freeranging vervet monkeys. American Society of Zoologists, 22, 519-529.

Cheney, D. L., \& Seyfarth, R. M. (1996). The function and mechanisms underlying baboon 'contact' barks. Animal Behaviour, 52, 507-518.

Conradt, L. (1998). Could asynchrony in activity between the sexes cause intersexual social segregation in ruminants? Proceedings of the Royal Society of London B: Biological Sciences, 265, 1359-1363.

Conradt, L., \& Roper, T. J. (2003). Group decision-making in animals. Nature, 421, 155-158. 
Conradt, L., \& Roper, T. J. (2005). Consensus decision making in animals. Trends in Ecology and Evolution, 20, 492-500.

Conradt, L., \& Roper, T. J. (2007). Democracy in animals: the evolution of shared group decisions. Proceedings of the Royal Society of London B: Biological Sciences, 274, 2317-2326.

Conradt, L., \& Roper, T. J. (2009). Conflicts of interest and the evolution of decision sharing. Philosophical Transactions of the Royal Society B: Biological Sciences, 364, 807-819.

Conradt, L., Krause, J., Couzin, I. D., \& Roper, T. J. (2009). "Leading according to need" in selforganizing groups. American Naturalist, 173, 304-312.

Couzin, I. D. (2009). Collective cognition in animal groups. Trends in Cognitive Sciences, 13, 36-43.

Dennett, D. C. (1971). Intentional systems. Journal of Philosophy, 68, 68-87.

Dostálková, I., \& Spinka, M. (2007). Synchronization of behaviour in pairs: the role of communication and consequences in timing. Animal Behaviour, 74, 1735-1742.

Dunbar, R. I. M. (1983). Structure of gelada baboon reproductive unit. 4. Integration at group level. Zeitschrift für Tierpsychologie, 63, 265-282.

Dunbar, R. I. M. (1988). Primate Social Systems. New York: Cornell University Press.

Dyer, J. R. G., Ioannou, C. C., Morrell, L. J., Croft, D. P., Couzin, I. D., Waters, D. A., et al. (2008). Consensus decision making in human crowds. Animal Behaviour, 75, 461-470.

Engh, A. L., Hoffmeier, R. R., Cheney, D. L., \& Seyfarth, R. M. (2006). Who, me? Can baboons infer the target of vocalizations? Animal Behaviour, 71, 381-387.

Ey, E., \& Fischer, J. (2011). Keeping in contact: Flexibility in calls of olive baboons. In V. Sommer \& C. Ross (Eds.), Primates of Gashaka: Socioecology and conservation in Nigeria's biodiversity hotspot (pp. 361-384). New York: Springer.

Ey, E., Rahn, C., Hammerschmidt, K., \& Fischer, J. (2009). Wild female olive baboons adapt their grunt vocalisations to environmental conditions. Ethology, 115, 493-503.

Fischer, J. (2008). Transmission of acquired information in nonhuman primates. In J. H. Byrne (Ed.), Learning and memory: A comprehensive reference (pp. 299-313). Oxford: Elsevier.

Fischer, J. (2011). Where is the information in animal communication? In R. Menzel \& J. Fischer (Eds.), Animal thinking: Contemporary issues in comparative cognition (pp. 151-161). Cambridge: MIT Press.

Fischer, J., \& Hammerschmidt, K. (2002). An overview of the Barbary macaque, Macaca sylvanus, vocal repertoire. Folia Primatologica, 73, 32-45.

Fischer, J., Hammerschmidt, K., Cheney, D. L., \& Seyfarth, R. M. (2001). Acoustic features of female chacma baboon barks. Ethology, 107, 33-54.

Fischer, J., Hammerschmidt, K., Cheney, D. L., \& Seyfarth, R. M. (2002). Acoustic features of male baboon loud calls: influences of context, age, and individuality. Journal of the Acoustical Society of America, 111, 1465-1474.

Galat-Luong, A., Galat, G., \& Hagall, S. (2006). The social and ecological flexibility of Guinea baboons: Implications for Guinea baboons social organization and male strategies. In L. Swedell \& S. Leigh (Eds.), Reproduction and fitness in baboons. Behavioral, ecological, and life history perspectives (pp. 105-121). New York: Springer.

Gigerenzer, G. (2001). Simple heuristics that make us smart. Oxford: Oxford University Press.

Gompper, M. E. (1996). Sociality and asociality in white-nosed coatis (Nasua narica): foraging costs and benefits. Behavioral Ecology, 7, 254-263.

Gregoire, G., Chate, H., \& Tu, Y. H. (2003). Moving and staying together without a leader. Physica D: Nonlinear Phenomena, 181, 157-170.

Grueter, C. C., \& Zinner, D. (2004). Nested societies. Convergent adaptations of baboons and snub-nosed monkeys? Primate Report, 70, 1-98.

Hare, B., Call, J., Agnetta, B., \& Tomasello, M. (2000). Chimpanzees know what conspecifics do and do not see. Animal Behaviour, 59, 771-785.

Heinroth, O. (1911). Beiträge zur Biologie, namentlich Ethologie und Psychologie der Anatiden Verhandlungen des V. Internationalen Ornithologen-Kongresses in Berlin, 1910, 332-340.

Hesler, N., \& Fischer, J. (2007). Gestural communication in Barbary macaques (Macaca sylvanus): An overview. In M. Tomasello \& J. Call (Eds.), The gestural communication of apes and monkeys (pp. 159-195). Mahwah: Lawrence Erlbaum Associates.

Jolly, C. J. (1993). Species, subspecies, and baboon systematics. In W. H. Kimbel \& L. B. Martin (Eds.), Species, species concepts, and primate evolution (pp. 67-101). New York: Plenum Press.

Kaminski, J., Call, J., \& Tomasello, M. (2008). Chimpanzees know what others know, but not what they believe. Cognition, 109, 224-234.

Kappeler, P. M., \& van Schaik, C. P. (2002). Evolution of primate social systems. International Journal of Primatology, 23, 707-740. 
King, A. J., \& Cowlishaw, G. (2009). Leaders, followers and group decision-making. Communicative \& Integrative Biology, 2, 147-150.

King, A. J. \& Sueur, C. (2011) Where next? Group coordination and collective decision making by primates. International Journal of Primatology. doi:10.1007/s10764-011-9526-7.

King, A. J., Douglas, C. M. S., Huchard, E., Isaac, N. J. B., \& Cowlishaw, G. (2008). Dominance and affiliation mediate despotism in a social primate. Current Biology, 18, 1833-1838.

Krause, J., \& Ruxton, G. (2002). Living in groups. Oxford: Oxford University Press.

Kummer, H. (1968). Social organization of hamadryas baboons: A field study. Chicago: The University of Chicago Press.

Kummer, H. (1990). The social system of hamadryas baboons and its presumable evolution. In M. T. de Mello, A. Whiten, \& R. W. Byrne (Eds.), Baboons: Ecology and behaviour. Use and care (pp. 4360). Brasilia, Brasil: Selected Proceedings of the XII Congress of the International Primatological Society 1988.

Kummer, H. (1995). In quest of the sacred baboon. Princeton: Princeton University Press.

Leca, J. P., Gunst, N., Thierry, B., \& Petit, O. (2003). Distributed leadership in semifree-ranging whitefaced capuchin monkeys. Animal Behaviour, 66, 1045-1052.

Lusseau, D., \& Conradt, L. (2009). The emergence of unshared consensus decisions in bottlenose dolphins. Behavioral Ecology and Sociobiology, 63, 1067-1077.

Maynard Smith, J., \& Harper, D. (2003). Animal signals. Oxford: Oxford University Press.

Mech, L. (1970). The wolf: The ecology and behavior of an endangered species. New York: Doubleday.

Meise, K., Keller, C., Cowlishaw, G., \& Fischer, J. (2011). Sources of acoustic variation: implications for production specificity and call categorization in chacma baboon (Papio ursinus) grunts. Journal of the Acoustical Society of America, 129, 1631-1641.

Melnick, D. J., \& Pearl, M. C. (1987). Cercopithecines in multimale groups: Genetic diversity and population structure. In B. B. Smuts, D. L. Cheney, R. M. Seyfarth, R. W. Wrangham, \& T. T. Struhsaker (Eds.), Primate societies (pp. 121-134). Chicago: The University of Chicago Press.

Meunier, H., Deneubourg, J., \& Petit, O. (2008). How many for dinner? Recruitment and monitoring by glances in capuchins. Primates, 49, 26-31.

Miller, M. B., \& Bassler, B. L. (2001). Quorum sensing in bacteria. Annual Review of Microbiology, 55, $165-199$.

Morgan, C. L. (1903). An introduction to comparative psychology (2nd ed.). London: Walter Scott.

Nadell, C. D., Xavier, J. B., Levin, S. A., \& Foster, K. R. (2008). The evolution of quorum sensing in bacterial biofilms. PLoS Biology, 6, 0171-0179.

Norton, G. W. (1986). Leadership: decision processes of group movement in yellow baboons. In J. G. Else \& P. C. Lee (Eds.), Primate ecology and conservation (pp. 145-156). Cambridge: Cambridge University Press.

Patzelt, A., Zinner, D., Fickenscher, G., Diedhou, S., Camara, B., Stahl, D., et al. (2011). Group composition of Guinea baboons (Papio papio) at a water place suggests a fluid fission-fusion social organisation. International Journal of Primatology, 32, 652-668.

Peterson, R. O., Jacobs, A. K., Drummer, T. D., Mech, L. D., \& Smith, D. W. (2002). Leadership behavior in relation to dominance and reproductive status in gray wolves, Canis lupus. Canadian Journal of Zoology, 80, 1405-1412.

Petit, O., \& Bon, R. (2010). Decision-making processes: the case of collective movements. Behavioural Processes, 84, 635-647.

Pratt, S. C., Mallon, E. B., Sumpter, D. J. T., \& Franks, N. R. (2002). Quorum sensing, recruitment, and collective decision-making during colony emigration by the ant Leptothorax albipennis. Behavioral Ecology and Sociobiology, 52, 117-127.

Premack, D., \& Woodruff, G. (1978). Does the chimpanzee have a theory of mind? Behavioral and Brain Sciences, 1, 515-526.

Pyritz, L. W., King, A. J., Sueur, C., \& Fichtel, C. (2011). Reaching a consensus: Terminology and concepts used in coordination and decision-making research. International Journal of Primatology. doi:10.1007/s10764-011-9524-9.

Ramos-Fernández, G., Pinachio-Guendulain, B., Perez, A. M., \& Boyer, D. (2011). No evidence of coordination between different subgroups in the fission-fusion society of spider monkeys (Ateles geoffroyi). International Journal of Primatology.

Ramseyer, A., Boissy, A., Dumont, B., \& Thierry, B. (2009). Decision making in group departures of sheep is a continuous process. Animal Behaviour, 78, 71-78.

Rasa, O. A. E. (1983). Dwarf mongoose and hornbill mutualism in the Taru desert, Kenya. Behavioral Ecology and Sociobiology, 12, 181-190. 
Ruckstuhl, K. E. (1999). To synchronise or not to synchronise: a dilemma for young bighorn males? Behaviour, 136, 805-818.

Schreier, A. L., \& Swedell, L. (2009). The fourth level of social structure in a multi-level society: ecological and social functions of clans in hamadryas baboons. American Journal of Primatology, 71, 948-955.

Scott-Phillips, T. C. (2008). Defining biological communication. Journal of Evolutionary Biology, 21, $387-395$.

Seed, A., Clayton, N., Carruthers, P., Dickinson, A., Glimcher, P. A., Güntürkün, O., et al. (2011). Planning, memory, and decision making. In R. Menzel \& J. Fischer (Eds.), Animal thinking: Contemporary issues in comparative cognition (pp. 121-147). Cambridge: MIT Press.

Seeley, T., \& Buhrman, S. (2001). Nest-site selection in honey bees: how well do swarms implement the "best-of-N" decision rule? Behavioral Ecology and Sociobiology, 49, 416-427.

Sellers, W. I., Hill, R. A., \& Logan, B. S. (2007). An agent-based model of group decision making in baboons. Philosophical Transactions of the Royal Society B: Biological Sciences, 362, 16991710 .

Seyfarth, R. M., \& Cheney, D. L. (2003). Signalers and receivers in animal communication. Annual Review of Psychology, 54, 145-173.

Sharman, M. (1981). Feeding, ranging and the social organisation of the Guinea baboon. Unpublished Ph.D. thesis, University of St. Andrews, St. Andrews, UK.

Stewart, K. J., \& Harcourt, A. H. (1994). Gorillas' vocalizations during rest periods: signals of impending departure? Behaviour, 130, 29-40.

Stolba, A. (1979). Entscheidungsfindung in Verbänden von Papio hamadryas. Unpublished Ph.D. thesis, Universität Zürich, Zürich.

Stueckle, S., \& Zinner, D. (2008). To follow or not to follow: decision making and leadership during the morning departure in chacma baboons. Animal Behaviour, 75, 1995-2004.

Sueur, C. \& Deneubourg, J. L. (2011). Self-organisation in primates: Understanding the rules underlying collective movements. International Journal of Primatology. doi:10.1007/s10764-011-9520-0.

Sueur, C., \& Petit, O. (2010). Signals use by leaders in Macaca tonkeana and Macaca mulatta: groupmate recruitment and behaviour monitoring. Animal Cognition, 13, 239-248.

Sueur, C., Petit, O., \& Deneubourg, J. L. (2009). Selective mimetism at departure in collective movements of Macaca tonkeana: An experimental and theoretical approach. Animal Behaviour, 78, 1087-1095.

Sueur, C., Deneubourg, J. L., Petit, O., \& Couzin, I. D. (2010). Differences in nutrient requirements imply a non-linear emergence of leaders in animal groups. PLoS Computational Biology, 6, e1000917.

Sueur, C., Deneubourg, J. L., \& Petit, O. (2011a). From the first intention movement to the last joiner: Macaques combine mimetic rules to optimize their collective decisions. Proceedings of the Royal Society B: Biological Sciences, 278, 1697-1704.

Sueur, C., King, A. J., Conradt, L., Kerth, G., Lusseau, D., Mettke-Hofmann, C., et al. (2011b). Collective decision-making and fission-fusion dynamics: A conceptual framework. Oikos. doi:10.1111/j.16000706.2011.19685.x.

Sumpter, D. J. T. (2006). The principles of collective animal behaviour. Philosophical Transactions of the Royal Society of London B: Biological Sciences, 361, 5-22.

Swedell, L. (2011). African papionins: Diversity of social organization and ecological flexibility. In C. J. Campbell, A. Fuentes, K. C. MacKinnon, S. K. Bearder, \& R. M. Stumpf (Eds.), Primates in perspective (pp. 241-277). New York: Oxford University Press.

Tomasello, M. (2008). Origins of human communication. Cambridge: MIT Press.

Tomasello, M., \& Call, J. (1997). Primate cognition. New York: Oxford University Press.

Trillmich, J., Fichtel, C., \& Kappeler, P. M. (2004). Coordination of group movements in wild Verreaux's sifakas (Propithecus verreauxi). Behaviour, 141, 1103-1120.

van Schaik, C. P. (1983). Why are diurnal primates living in groups? Behaviour, 87, 120-144.

Watts, D. (2000). Mountain gorilla habitat use strategies and group movements. In S. Boinski \& P. A. Garber (Eds.), On the move: How and why animals travel in groups (pp. 351-374). Chicago: The University of Chicago Press.

Wheeler, B., Searcy, W. A., Christiansen, M. H., Corballis, M. C., Fischer, J., Grüter, C., et al. (2011). Communication. In R. Menzel \& J. Fischer (Eds.), Animal thinking: Contemporary issues in comparative cognition (pp. 187-205). Cambridge: MIT.

Wrangham, R. W. (1980). An ecological model of female-bonded primate groups. Behaviour, 75, 262-300.

Zinner, D., Peláez, F., \& Torkler, F. (2001). Group composition and adult-sex ratio of hamadryas baboons (Papio hamadryas hamadryas) in Eritrea. International Journal of Primatology, 22, 415430 . 